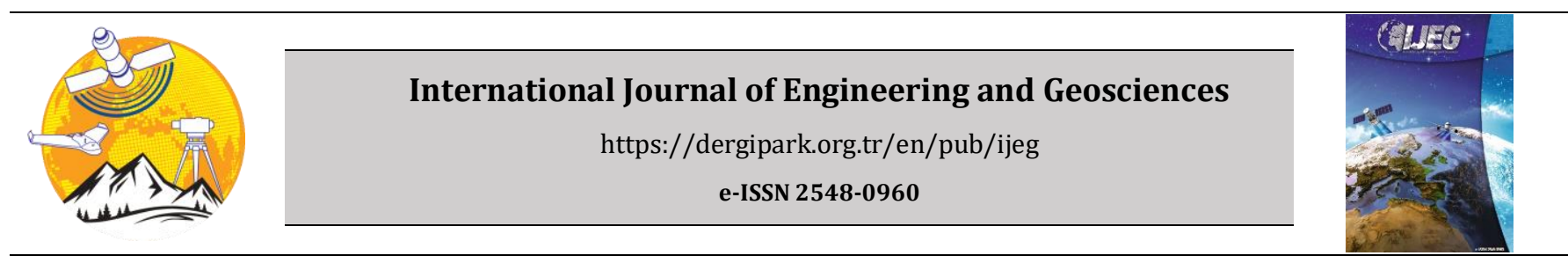

\title{
Determining the relationship between the slope and directional distribution of the UAV point cloud and the accuracy of various IDW interpolation
}

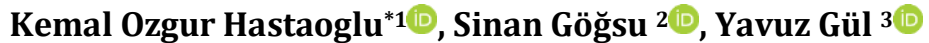 \\ ${ }_{1}^{1}$ Sivas Cumhuriyet University, Engineering Faculty, Dept. of Geomatics Engineering, Sivas, Turkey \\ ${ }^{2}$ Sivas Directorate of Cadastre, General Directorate of Land Registry and Cadastre, Sivas, Turkey \\ ${ }^{3}$ Sivas Cumhuriyet University, Engineering Faculty, Dept. of Mining Engineering, Sivas, Turkey
}

\author{
Keywords \\ Interpolation \\ UAV point cloud \\ Shepard \\ Slope effect \\ Anisotropy
}

\begin{abstract}
Inverse Distance Weighted (IDW) based interpolation method is also widely used in earth science studies. In the classical IDW method, the directional distribution of the reference points around the point to be estimated within the critical circle and the slope differences are not taken into consideration. On the other hand, in the IDW-based method developed by Shepard, the ratio of the distances of the reference points within the critical circle to the critical circle radius (r), the anisotropy and the slope differences are taken into consideration. In this study, the results of the classical IDW method and Shepard method were compared to increase the accuracy of interpolation produced from UAV data. A software has been developed to make these comparisons in more detail. The classical IDW and Shepard based interpolation methods used in this software takes into consideration the anisotropy, the slope differences and the ratio of the distances to the critical circle radius. In this study, UAV flights were performed in three different study areas with different topographic features and 3D point cloud data were obtained in order to make detailed analyzes. Using developed software, data from three different study areas have been tested and the results from different Shepard interpolation models have been discussed. The major contribution of this paper is in evaluation of various IDW options when applied to UAV point data. As a result, especially in geodetic studies form UAV data, it was observed that the results improved with $11 \%$ to $37 \%$ by using the Shepard method with the suitable power parameter value considering the directional distribution of the reference points in the critical circle and the slope differences.
\end{abstract}

\section{INTRODUCTION}

IDW interpolation method is one of the most commonly used deterministic models in spatial interpolation models (Lu and Wong 2008). IDW method is widely preferred because it has a simple structure in calculations and programming. Many researchers have done different studies on the effect of the interpolation method on DEM accuracy. In these studies, the IDWbased interpolation method was compared with other interpolation methods, and the weak and successful qualifications of the IDW method were tried to be determined. (Tran and Nguven 2008; Bater and Coops 2009; Guo et al. 2010; Arun 2013; Setianto and Triandini
2013; Ismail et al. 2016; Habib et al. 2018.; Graham et al. 2020).

Today, the IDW interpolation method is used as the standard in many software. In the IDW method used in these software's, the power parameter value $(\mathrm{u})$ is usually taken as 2 (Brimicombe 2009; Stafford 2013; Michael 2020; Envir. Sys. Res. Inst. 2020). However, according to the general characteristics of the field studied and the data distribution, the power parameter value that gives the most appropriate result varies. Therefore, it is necessary to determine the " $u$ " value specific to each study area. Lu and Wong (2008), in the IDW method, they suggested that the value of the weighting parameter be allowed to vary according to the spatial pattern of the sampled points in the

\section{* Corresponding author}

*(khastaoglu@cumhuriyet.edu.tr) ORCID ID 0000-0002-5077-5889

(sinangogsu@gmail.com) ORCID ID 0000-0003-3853-4473

(ygul@cumhuriyet.edu.tr) ORCID ID 0000-0002-2969-577X
Cite this article

Hastaoglu K O, Gogsu S \& Gul Y (2022). Determining the relationship between the slope and directional distribution of the UAV point cloud and the accuracy of various IDW interpolation. International Journal of Engineering and Geosciences, 7(2), 161-173 
neighborhood. They developed an algorithm to search for "optimal" adaptive distance-decay parameters. They concluded that adaptive IDW performs better than the constant parameter method in most cases and better than ordinary kriging in one of their empirical studies.

The main purpose of this article is to investigate the effect of slope difference and directional distribution between reference points and interpolation points on the accuracy of various IDW interpolation methods. For this purpose, UAV point cloud data were used in the study. Within the scope of this study, it is aimed to develop software that can perform estimates with both the classical IDW method and the Shepard method. For these purposes, a software named IDW_OPTIMAL was developed in this study. Using the IDW_OPTIMAL software for UAV point clouds in three different study sites, the most appropriate u value and the most suitable IDW-based interpolation method were determined and the results were examined. Thanks to the developed software, the results regarding the Shepard method approaches, which take into account the ratio of the distance of the points falling in the critical circle to the critical circle radius, the directional distribution, and the slope differences, were examined in detail. In addition, the directional distribution of reference points and the effects of slope differences on interpolation results were examined in detail. As a result of these evaluations, it was observed that the results were improved between $11 \%$ and $37 \%$ when the most appropriate $u$ value and the most suitable IDW-based interpolation method were used for the study area.

In many previous studies, the advantages and disadvantages of the classical IDW method compared to other interpolation methods were examined in detail. However, the Shepard method was not discussed in detail in any of these studies. The accuracy assessment and comparative analysis of IDW, Spline and Kriging methods in the spatial interpolation of the earth was investigated by Ikechukwu et al. (2017). It is stated that according to the data set used, the IDW method is more sensitive than the Kriging method, and the Spline method has better results than the other two methods. On the other hand, Agüera et al. (2019) produced DTMs with different grid size from 3D point clouds data using four different interpolation methods. It was seen that the IDW method for each interpolation method and each density is the interpolation method that gives the best accuracy for all densities and GS combinations. Ferreira et al. (2017) analyzed the efficiency of IDW and Universal Kriging by reducing the number of sample points in computational representation of bathymetric surfaces. As a result, they determined the superiority of the inefficiency of Universal Kriging method in creating DMD in bathymetric data.

In addition, some studies have conducted research on the effect of power parameter on accuracy in IDW method. Chen and Liu (2012) determined the most appropriate radius of effect and power parameter values for the IDW method. It has been determined that the radius of effect is between $10-30 \mathrm{~km}$ and the power parameter $(\alpha)$ is in the range of $0-5$. Zhou et al. (2017), a new IDW method has been proposed by designing a topographic factor in the calculation of the appropriate power parameter and weight, based on the principle of the IDW method. The proposed IDW method compared to the classical IDW method has been shown to improve interpolation accuracy. As a result of this study, with the weight model considering topographic factors, the results were improved by $9 \%$ when the power parameter was 2 , and a $12 \%$ improvement was observed in the results when the power parameter was 3 . However, the effect of the radius of the critical circle and the directional distribution of the control points on the accuracy are ignored in this study. In our study, besides topographic effect and power parameter, directional distribution and critical circle radius were taken into consideration and improvements of up to $37 \%$ were observed in the results.

In the spatial analysis section of many GIS studies, Shepard (1968) was cited (Paul et al. 2019; Mohamed et al. 2018; Sarkar et al. 2016; Welch et al. 2014; Wang and Huang 2012) In these studies only the classical IDW method was used, and the directional distribution and slope distribution features proposed by Shepard were ignored. The reason for this is that there is only the classic IDW method in the GIS software's used. In addition, it is mentioned that Shepard method is used when testing the success of interpolation methods in many socio-economic, hydrological, meteorological and environmental pollution GIS studies. (Wu et al. 2019; Meng et al. 2019; Liao et al. 2018; Das et al. 2017) In these studies, the directional distribution and slope distribution features proposed by Shepard were also ignored.

\section{INVERSE DISTANCE WEIGHTED INTERPOLATION METHOD (IDW)}

In this method, the distances between the interpolation points and the reference points are used in the weight calculation to estimate the unknown points. In the method, it is aimed that the reference points near the point to be interpolated have more weight than the distant reference points.

A different interpolation approach using weighted averages was developed in the study conducted by Shepard in 1968. As a result of this approach, he has developed an IDW based interpolation method that takes account of selection of reference points, directional distributions and slope differences. The interpolation value at any $\mathrm{P}$ point in the plane is a weighted average of the values at the Di reference points. The interpolation value at the $\mathrm{P}$ point is calculated by the following Eq.1.

$f_{1}(P)= \begin{cases}{\left[\sum_{i=1}^{N}\left(d_{i}\right)^{-u} \cdot Z_{i}\right] /\left[\sum_{i=1}^{N}\left(d_{i}\right)^{-u}\right]} & d_{i} \neq 0,(u>0) \\ Z_{i} & d_{i}=0\end{cases}$

In Eq. $1 \mathrm{Z}_{\mathrm{i}}$ is the value at the reference points and di is the distance between the P point and the Di reference points. Depending on the function, point $\mathrm{P}$ is approaching the reference point $\mathrm{Di}$ and if $\mathrm{di}=0$ it takes the value $f(P)=Z_{i}$.

In the weighting function in Eq. 1, the calculation can be facilitated by eliminating the remote reference points. A maximum of ten points and minimum of four points is selected to limit the calculation complexity and amount. Also, a first search radius $r$ is created based on the total 
density of the data points. If the area of the largest polygon surrounded by the reference points is $\mathrm{A}$, the total number of reference points $\mathrm{N}$ is defined as follows, with an average of seven reference points in the circle in the radius $r$ (Shepard 1968).

$\pi r^{2}=7 *\left(\frac{A}{N}\right)$

After selecting the reference points that fall into the critical circle, the new weighting functions $S_{i}=S\left(d_{i}\right)$, of the effect of di distances on the interpolation process for each $D_{i} \in C^{\prime}$ between the interpolation point $P$ and the reference points can be defined.

$S(d)= \begin{cases}\frac{1}{d} & 0 \leq d \leq \frac{r^{\prime}}{3} \\ \frac{27}{4 r^{\prime}} \cdot\left(\frac{d}{r^{\prime}}-1\right)^{2} & \frac{r^{\prime}}{3}<d \leq r^{\prime} \\ C_{P}^{10} & r^{\prime}<d\end{cases}$

In Eq.3 function has been defined as permanently distinguishable all over $\mathrm{d}>0$. $\mathrm{S}(\mathrm{d})=0$ for $\mathrm{d}>\mathrm{r}^{\prime}$. In Shepard (1968) it is stated that a direction factor is required in addition to the distance factor in defining weights to improve the interpolation process. The weighting term that takes into account the direction factor for each reference point near the interpolation point at the $\mathrm{P}$ position would be as in Eq. 4.

$t_{i}=\left[\sum_{D_{j} \in C^{\prime}} S_{j}\left[1-\cos \left(D_{i} P D_{j}\right)\right]\right] /\left[\sum_{D_{j} \in C^{\prime}} S_{j}\right]$

$0 \leq t_{i}<2$ since $-1 \leq \cos (\theta) \leq 1$ for all $\theta$ angles. The cosine function defined in Eq.4 was used as a direction measure due to both convenience and ease of calculation. In interpolation, the effect of the points close to P should be more than the distant points. For this reason, distance factor $S_{j}$ should be included in the numerator and denominator. A new weight function that takes the direction into account is defined as in Eq.6.

$w_{i}=\left(S_{i}\right)^{2} \cdot\left(1+t_{i}\right)$

In Eq.5, the slope for each $D_{i}$ in the interpolation function is assumed to be zero. The interpolation function must be rearranged to take into account the slope effect in each $D_{i}$. First, for each data point $D_{i}$, the constants $\mathrm{Ai}$ and $\mathrm{Bi}$ representing the desired slope in the $\mathrm{x}$ and $\mathrm{y}$ directions in $\mathrm{D}_{\mathrm{i}}$ are determined. With $C_{-}{ }^{\prime \prime}=C_{D i}^{\prime}-\left\{D_{i}\right\} \quad, A_{i}$ and $B_{i}$ constants are calculated as in Shepard, 1968. A parameter $\mathrm{V}$, which is then the combination of the $x$ and $y$ directions, with the total range of $\mathrm{Z}_{\mathrm{i}}$ and the distance dimension relative to the desired slopes, is expressed as in Shepard, 1968.

Parameter $\mathrm{v}$ limits the maximum effect of slope terms to $\mathrm{Z}$ value obtained by interpolation. To add the effect of the slope on the interpolation value at $\mathrm{P}(\mathrm{x}, \mathrm{y})$, a $\Delta \mathrm{Z}_{\mathrm{i}}$ increment value for each $\mathrm{D}_{\mathrm{i}} \in \mathrm{CP}$ is calculated as in Eq. 6 as a function of $P$.

$\Delta Z_{i}=\left[A_{i} \cdot\left(x-X_{i}\right)+B_{i} \cdot\left(y-Y_{i}\right)\right] \cdot\left[\frac{v}{v+d_{i}}\right]$

\section{MATERIAL AND METHOD}

\subsection{Study Area}

Since the UAV dataset contains cm-level point cloud data, it is possible to sample the UAV data at the desired frequency and density. In our study, it was preferred to use UAV data, especially in terms of needing data with different topographic features and directional distributions and analyzing the results with more data sets. In addition to this, UAV technology has started to be used instead of classical surveying and mapping methods. The time, cost and accuracy advantages of the UAV method have made the use of the method especially common in DEM creation. UAV data were used as test data because the method is new and up-to-date and it is convenient to create a sufficient number of datasets for analyses.

Three different sites with different topographic features were selected as the study area. In order to investigate the effect of directional distribution and topographic effect on the accuracy of the IDW method, these study areas with different topographic characteristics were preferred. The study areas are Hamal, Kızılcakent and Eliktekke (Figure 1). Point clouds obtained by the UAV photogrammetry method related to the study areas were used as a data set. Since the Ground Sample Distance (GSD) value in the point cloud data is less than $7 \mathrm{~cm}$, interpolation cannot be performed using the whole data set, so the data set has been diluted. If the whole data set is used, the interpolation process will lose its meaning as the distance between the interpolation point and reference points will be almost zero. For each study area, first of all, the workspaces with the desired topographic structure were cut and smaller workspaces were created, and then random point clouds were selected for these new study areas with maximum $10 \mathrm{~m}$ intervals. Thus, the point cloud data is diluted and the data are made suitable for interpolation.

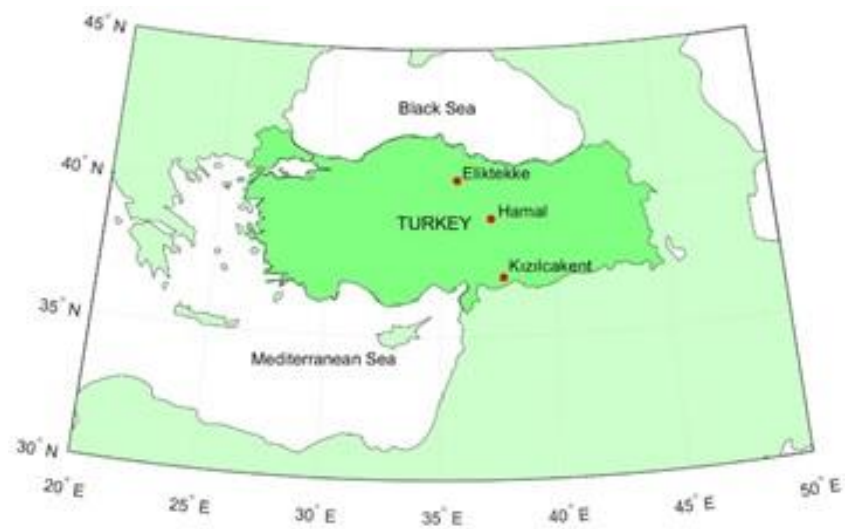

Figure 1. The locations of study areas

Detailed information on the study areas is given in Table 1. The reference points, control points and point cloud on the study areas in Figure 2,3 and 4 are presented. 
Table 1. Information of study areas

\begin{tabular}{llllll}
\hline \multirow{2}{*}{$\begin{array}{l}\text { Study } \\
\text { Area }\end{array}$} & $\begin{array}{l}\text { Area } \\
\text { (he) }\end{array}$ & \multicolumn{2}{c}{ Points } & $\begin{array}{l}\text { Change of } \\
\text { the slope }\end{array}$ \\
\cline { 3 - 6 } & & $\begin{array}{l}\text { Control } \\
\text { (number) }\end{array}$ & $\begin{array}{l}\text { Referance } \\
\text { (number) }\end{array}$ & $\begin{array}{l}\text { E-W } \\
(\%)\end{array}$ & $\begin{array}{l}\mathrm{N}-\mathrm{S} \\
(\%)\end{array}$ \\
\hline Hamal & 168 & 180 & 19594 & 15 & 5 \\
\hline Kizılcakent & 98 & 250 & 19036 & 12 & 2 \\
\hline Eliktekke & 38 & 73 & 11231 & 18 & 25 \\
\hline
\end{tabular}

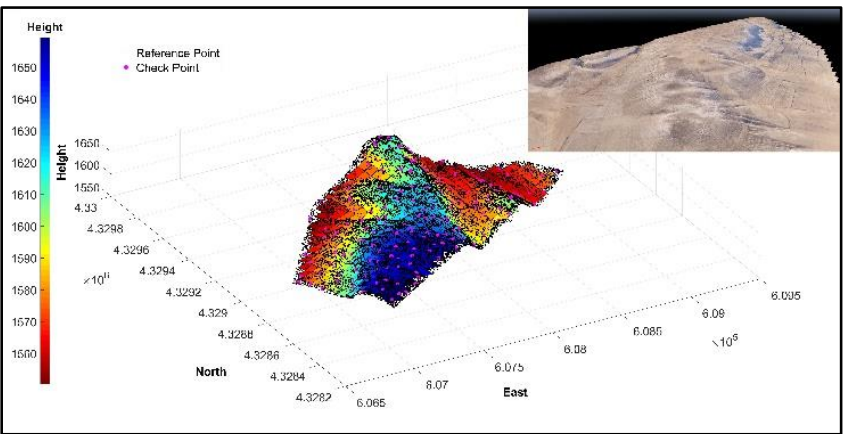

Figure 2. Hamal study area

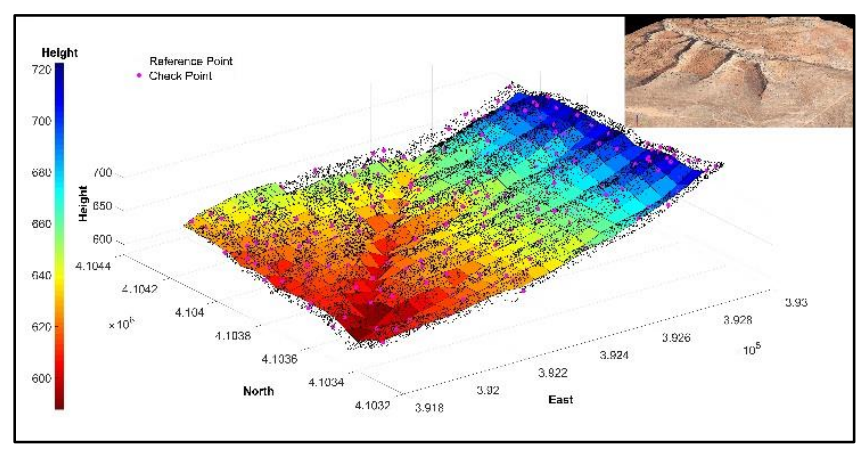

Figure 3. Kizılkent study area

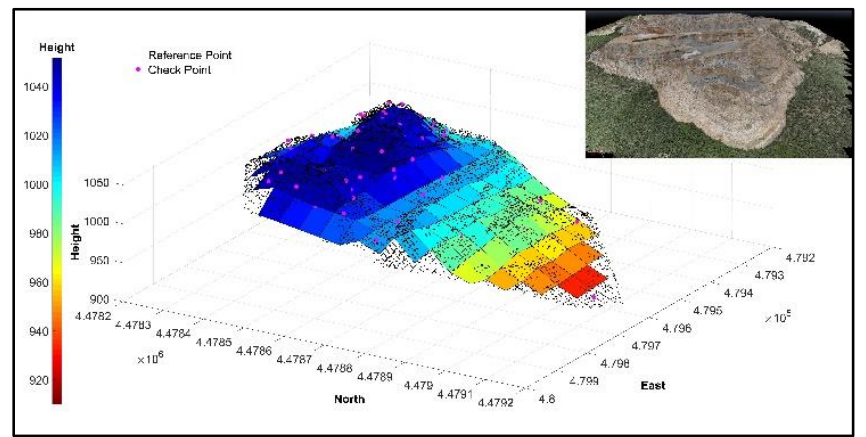

Figure 4. Eliktekke study area

\subsection{UAV Photogrammetry Data Acquisition and Processing}

In accordance with the purposes mentioned above, flights were carried out at the three different study areas. For the Eliktekke study area, flights were carried out using hexacopter according to the information given in Table 2. On the other hand, flights were carried out using quadcopter according to the information given in Table 2. All technical equipment used for flights belongs to GEOMINE Company. PIX4D software licensed by GEOMINE was used to evaluate aerial photographs. In the study areas, the number of ground control points (GCPs) given in Table 2 were installed and measured by the CORS GNSS method. The knowledge of UAV data acquisition and processing are given in Table 2 .
Table 2. The knowledge of UAV data acquisition and processing

\begin{tabular}{llll}
\hline Study Area & Eliktekke & Hamal & Kizllcakent \\
\hline GSD & $1.44 \mathrm{~cm}$ & $5.23 \mathrm{~cm}$ & $7.26 \mathrm{~cm}$ \\
\hline Area Covered & $80 \mathrm{ha}$ & $310 \mathrm{ha}$ & $250 \mathrm{ha}$ \\
\hline GCP Number & 12 & 43 & 50 \\
\hline $\begin{array}{l}\text { GCP mean } \\
\text { RMSerror }\end{array}$ & $0.7 \mathrm{~cm}$ & $3.8 \mathrm{~cm}$ & $6.0 \mathrm{~cm}$ \\
\hline $\begin{array}{l}\text { Num. of 3D } \\
\text { Dens. Points }\end{array}$ & 451924568 & 107116721 & 81632904 \\
\hline $\begin{array}{l}\text { Cam. Spec. } \\
\text { Im. format }\end{array}$ & Sony A7R & SonyA6000 & SonyA6000 \\
Focal Length & $3560 \times 4912$ & $4608 \times 3456$ & $4608 \times 3456$ \\
\hline Flying speed & $5.9 \mathrm{~m} / \mathrm{s}$ & $16 \mathrm{~mm}$ & $16 \mathrm{~mm}$ \\
\hline $\begin{array}{l}\text { For. and side } \\
\text { overlap (\%) }\end{array}$ & $80 / 60$ & $80 / 60$ & $11.0 \mathrm{~m} / \mathrm{s}$ \\
\hline $\begin{array}{l}\text { Number of } \\
\text { Images }\end{array}$ & 1865 & 911 & $80 / 60$ \\
\hline
\end{tabular}

In order to examine the effect of point cloud accuracy on interpolation methods, Eliktekke was flown to have a lower GSD value compared to the other two fields. Point cloud accuracy obtained with UAV photogrammetry is specified as (1-2) $\times$ GSD for horizontal and (1-3) $\times$ GSD for vertical in PIX4D program documents (Url-1, 2018). Since GSDs for Eliktekke, Hamal and Kizılcakent study areas are 1.4, 5.2 and $7.3 \mathrm{~cm}$ / pixel, respectively, the expected accuracy of point clouds in these study areas are varied between 1.4-2.8, 5.2-10.4 and 7.3-14.6 cm horizontally and 1.4-4.2 5.2-15.6 and 7.3-21.9 cm vertically, respectively.

Some of the point cloud data were selected as control points and these control points were estimated. The estimations were made by using both Standard IDW and Shepard method approaches for different power parameter values. Root mean Squares (RMS) were calculated by taking into account the differences between the estimated values and known values. The approach with which the smallest RMS is obtained has been determined as the most suitable method since the RMS value approaching zero means that the accuracy of the estimation is high. According to the calculated RMS values, the outliers that are not suitable for the standard normal distribution are determined. Since the number of data is greater than $40(n>40)$, the two-sided standard normal distribution value $(z= \pm 1.96)$ was used for the 95\% confidence level $(\alpha=0.05)$ in the determination and removal of outliers. When the outliers are examined in detail, it has been observed that these points are usually points that show a sudden change in height (tree, house, hole, etc.). Therefore, these points were excluded from the evaluation. The accuracy of the method is determined using RMS values recalculated using data that are free from outliers.

\subsection{IDW_OPTIMAL Software}

A Matlab-based program has been developed that can take into account the directional distribution of reference points and slope differences in the Shepard interpolation method. Thanks to this program, calculations are made with different IDW-based options. 
In the first stage of the software, the boundaries of the study area (A) are calculated by determining according to the reference point set. Then, the location information of the interpolation points is entered by the user and the interpolation points remaining in the study area are determined. In Shepard method in software, critical circle radius ( $\mathrm{r}$ ) is calculated and reference points around interpolation point are determined.

Interpolation methods in the software are standard IDW (IDW std $_{\text {) }}$ and Shepard method. In the second stage, the interpolation method is selected. Shepard method has been accepted as three approaches in itself. These are, respectively, according to the weights calculated without the direction and slope factor (SHPstd: Shepard Standard), using only the direction factor (SHPDD: Shepard Directional Distribution) and by considering the direction and slope factor together (SHP ${ }_{D D+S D}$ : Shepard Directional Distribution + Slope Differences) interpolation methods.

\subsubsection{Interpolation According to Standard IDW (IDW std) Method}

In this method, critical circle in Shepard method is taken as the basis for selection of reference points. The $\mathrm{Z}$ value of the interpolation point are estimated by calculating the weights with the weight function in Eq.1 according to the distance between the interpolation point and reference points in the critical circle. The flow diagram of this process is shown in Figure 5. The weight calculation is a function of the inverse of the distance in degrees $u$, the value of the $u$ parameter is determined by the user.

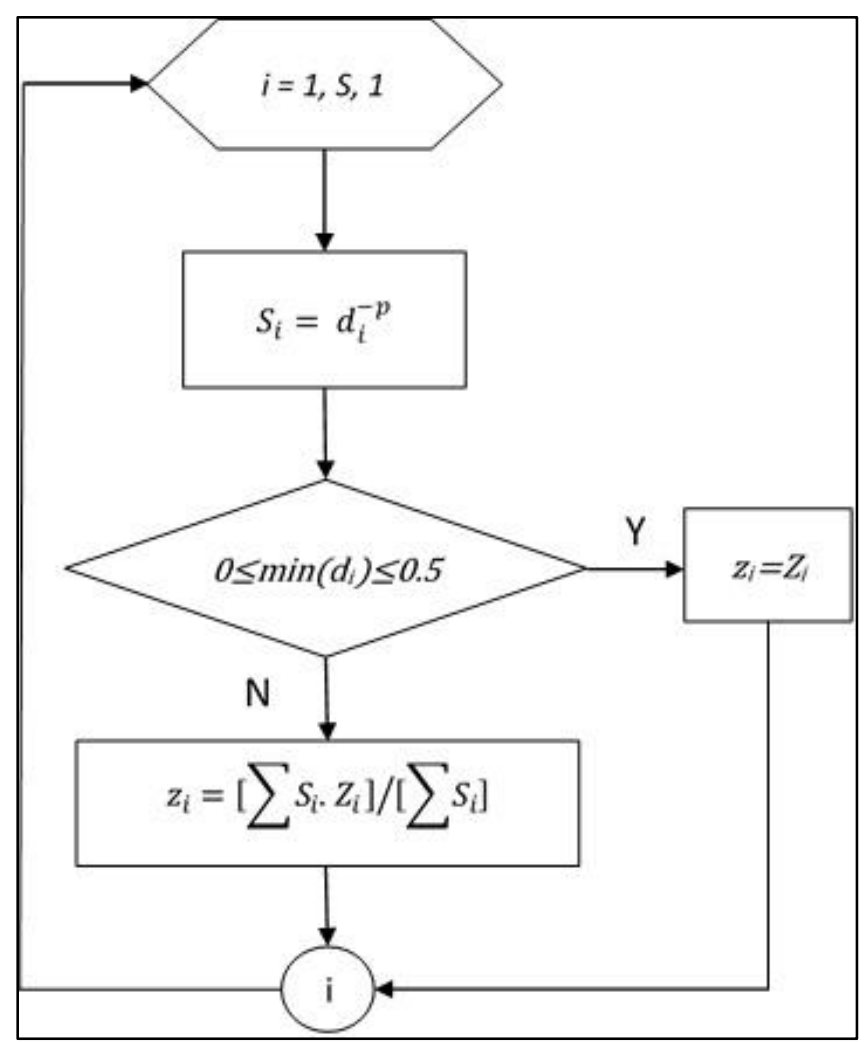

Figure 5. Standard IDW method weight calculation flow diagram

\subsubsection{Interpolation with Shepard Method}

Shepard interpolation method is examined according to three different approaches. In the first approach (SHP std $_{\text {) }}$, weights are calculated according to the function of the only inverse distance by ignoring the direction and slope factor, in the second approach ( $\mathrm{SHP}_{\mathrm{DD}}$ ), weighting is done by including the direction factor, In the third approach ( $\left.\mathrm{SHP}_{\mathrm{DD}+\mathrm{SD}}\right)$, interpolation is performed according to the weights calculated by evaluating the direction and slope factor together. Calculations were performed for each of these approaches using the developed software.

\subsubsection{Weighting according to only inverse distance for the Shepard Method (SHP std)}

The first approach of the Shepard method ( $\left.\mathrm{SHP}_{\text {std }}\right)$ is the interpolation process without direction and slope factor. In this approach, weights are calculated by evaluating the ratio (Eq. 2) of the distance between the reference points and interpolation points in the critical circle to the critical circle radius (Figure 6). After the weight calculation, interpolation is performed according to the interpolation function in Eq. 3. The flow diagram of this process is shown in Figure 7.

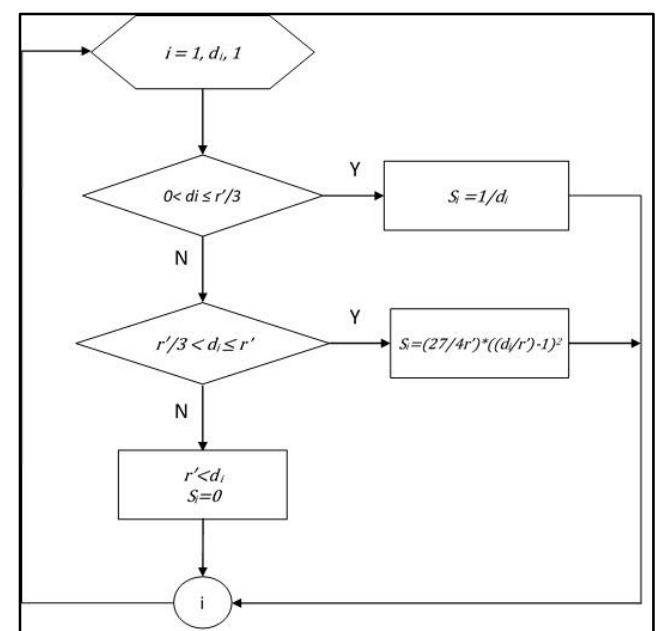

Figure 6. Weight calculation algorithm according to the ratio of the distance to the critical circle radius.

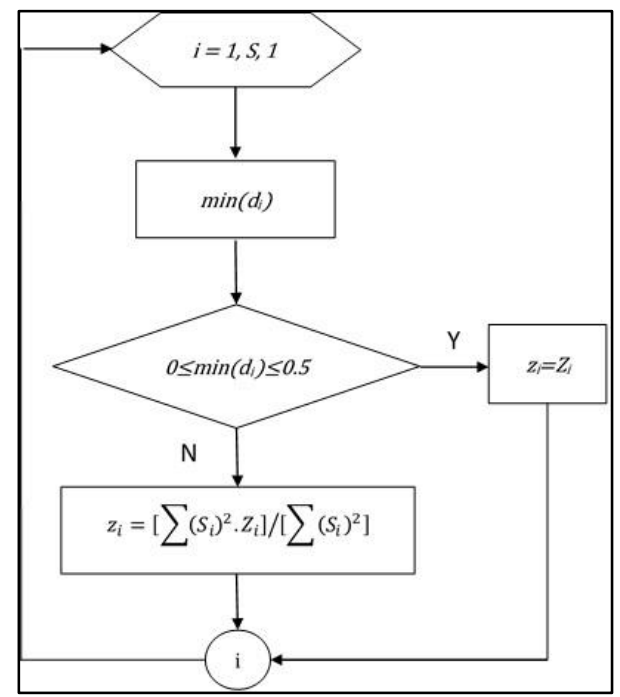

Figure 7. Interpolation points estimation algorithm 


\subsubsection{Weighting according to directional distribution for Shepard Method (SHPDD)}

The interpolation process in this approach $\left(\mathrm{SHP}_{\mathrm{DD}}\right)$ is based on the recalculation of the $\mathrm{S}$ weights, which are calculated by only inverse distance in the first approach, by taking into account the directional distributions of the reference points in the critical circle. The weight calculation algorithm after the addition of the direction factor is shown in Figure 8.

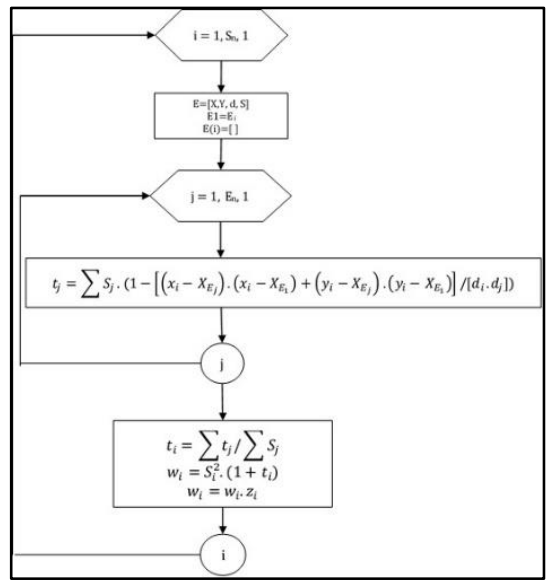

Figure 8. Weight function algorithm obtained by including direction factor.

\subsubsection{Weighting according to directional distribution and slope difference for Shepard Method (SHPDD+SD)}

In the third approach of the Shepard method $\left(\mathrm{SHP}_{\mathrm{DD}}+\mathrm{SD}\right)$, besides the directional distribution of the reference points, weighting is done by adding the slope differences between the reference points to the weight function. Figure 9 shows the processing algorithm. After the weights are calculated according to the direction and slope factors, interpolation calculation is made according to Eq. 6. The algorithm of this process is given in Figure 10.

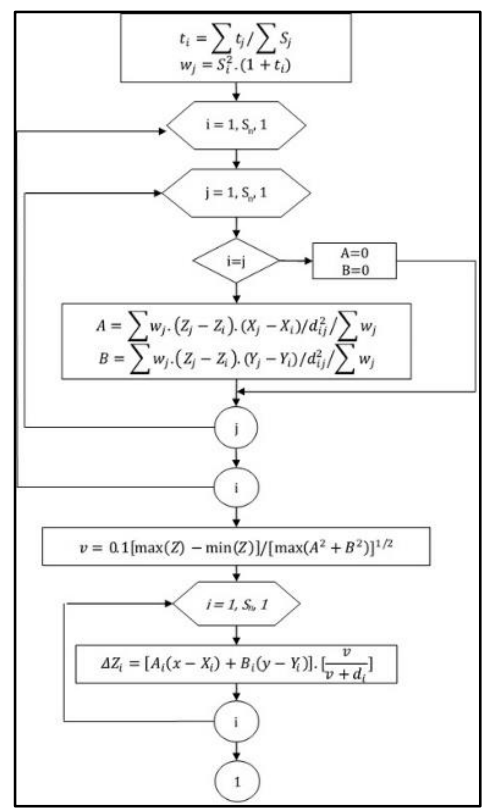

Figure 9. Weight function algorithm according to direction and slope factors.

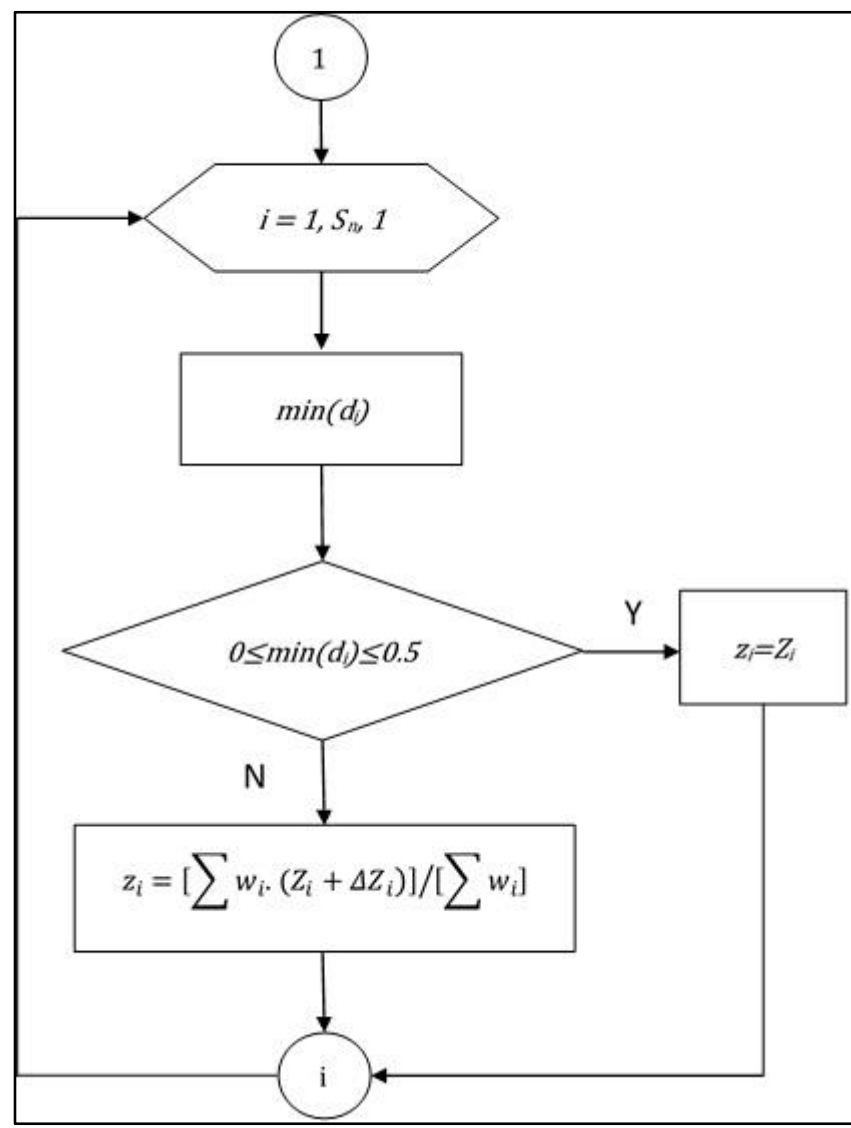

Figure 10. Interpolation process algorithm according to the direction and slope factor.

\subsection{Evaluation of the data with the software and determining the most appropriate interpolation approach}

Data in the point cloud cluster produced by UAV photogrammetry of three different study sites are used as input data in the software (IDW_OPTIMAL) developed (Figure 11). The points to be interpolated are points selected from the point cloud set in a random distribution and whose height values are known.

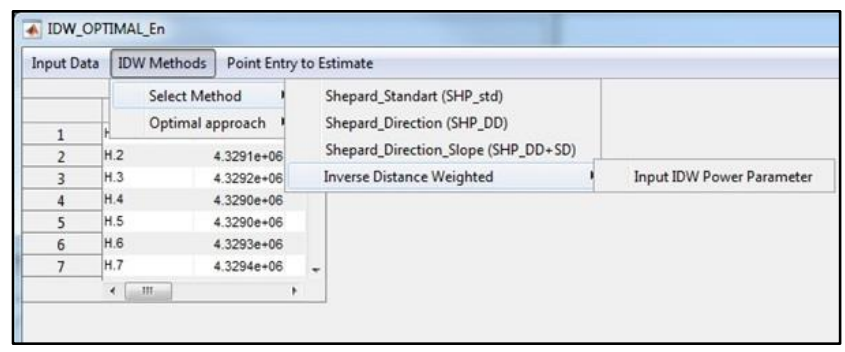

Figure 11. Selection of interpolation method

The data of Hamal, Kizllcakent and Eliktekke study areas were evaluated in the software and the estimation results of IDW ${ }_{\text {std, }}$ SHP $_{\text {std, }}$ SHPDD and SHPDD+SD approaches were recorded. (Figure 11). RMS values for each method were calculated because the predicted interpolation points are control points.

In Table 3, RMSs calculated after removing outliers are given for the different power parameter $(\mathrm{u})$ values $(u=1,2,3,4)$ in the $I_{\text {std }}$ approach and for the standart power parameter value $(\mathrm{u}=2)$ in the three approaches of the Shepard method. 
Table 3. Accuracy of interpolation results according to standard IDW and Shepard approaches (after the outliers are removed)

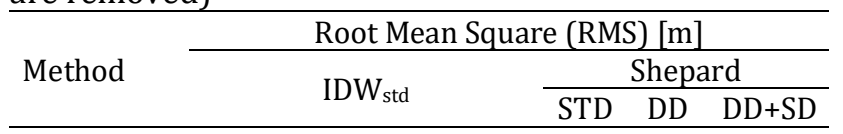

\begin{tabular}{lccccccc}
\hline $\begin{array}{l}\text { Study } \\
\begin{array}{l}\text { area/Pow. } \\
\text { Par. (u) }\end{array}\end{array}$ & $u=1^{*}$ & $u=2^{*}$ & $u=3^{*}$ & $u=4^{*}$ & $u=2$ & $u=2$ & $u=2$ \\
\hline Ham. & 0.36 & 0.32 & 0.33 & 0.35 & 0.38 & 0.35 & 0.32 \\
\hline Kizll. & 0.52 & 0.52 & 0.53 & 0.53 & 0.61 & 0.59 & 0.51 \\
\hline Elik. & 0.85 & 0.81 & 0.81 & 0.82 & 0.90 & 0.90 & 0.81 \\
\hline
\end{tabular}

*User-defined power parameter $(u=1,2,3,4)$

When Table 3 is examined, it is seen that for the $u=2$ value generally used in the application the results obtained with the IDW $_{\text {std }}$ approach are close to the results of the Shepard approaches considering the direction and slope factor. Although the RMS values are slightly smaller in the Shepard approaches than the IDW $_{\text {std }}$ approach, there is no significant improvement $(<5$ $\mathrm{mm}$ ) between the values.

Table 4. Interpolation RMS values, GSD and accuracy of UAV results and change of slope of study areas

\begin{tabular}{llllll} 
& & \multicolumn{2}{c}{ Accuracy } & \multicolumn{2}{c}{ Change of the slope } \\
\cline { 3 - 6 } $\begin{array}{l}\text { Study } \\
\text { Area }\end{array}$ & $\begin{array}{l}\text { RMS } \\
(\mathrm{m})\end{array}$ & $\begin{array}{l}\text { GSD } \\
(\mathrm{m})\end{array}$ & $\begin{array}{l}\text { Max. } \\
\text { Vertical } \\
\text { Pos.(m) }\end{array}$ & $\begin{array}{l}\text { East- } \\
\text { West } \\
(\%)\end{array}$ & $\begin{array}{l}\text { North- } \\
\text { South } \\
(\%)\end{array}$ \\
\hline Ham. & 0.363 & 0.052 & 0.156 & 15 & 5 \\
\hline Kizil. & 0.519 & 0.073 & 0.219 & 12 & 2 \\
\hline Elik. & 0.849 & 0.014 & 0.042 & 18 & 25 \\
\hline
\end{tabular}

Table 4 shows RMS values of interpolation results according to standard IDW $(\mathrm{u}=1)$. In addition, GSDs, expected accuracy of maximum vertical position error of UAV results and the directions of change of the slope across the north-south and east-west direction are given for each study area. The Eliktekke study area has the highest RMS value, although it has the lowest expected accuracy of vertical position error. The main reason for this is that the change of the slope across the north-south and east-west direction are very high in the Eliktekke study area. As can be clearly seen here, there is a very large relationship between the slope change and interpolation accuracy. Although the UAV GSD values are 4-5 times higher in the Hamal and Kizllcakent study sites compared to the Eliktekke study area, the interpolation RMS values are much lower. The Hamal and Kizılcakent study areas interpolation RMS values are approximately 2.5 times the expected accuracy of vertical position error values. The slope changes in these two study areas are very similar to each other. The interpolation RMS values are 2.5 times the expected accuracy of vertical position error in the areas where the slope shows little change (between 12-15\% for north-south and between 2-5\% for east west), while this result is 21 times for the Eliktekke field. While interpolation accuracy is directly related to GSD in areas where the slope shows little variation, this relationship loses its importance in areas with high slope variation ( $25 \%$ for north-south and $18 \%$ for east west).

In case the interpolation points are control points, the software determines the most appropriate method according to the smallest value from the RMS obtained according to different power parameter values. For the three study areas, the most appropriate method has been determined for the power parameter values in the range of 1-30 (1,2,3 ... 30). The RMS values obtained after removing outliers are given in Table 5.

Table 5. The most appropriate power parameters and minimum RMS values (after the outliers are removed)

\begin{tabular}{|c|c|c|c|c|c|}
\hline \multirow[b]{2}{*}{ Method } & \multirow[b]{2}{*}{ IDW $_{\text {std }}$} & \multicolumn{4}{|c|}{ Shepard } \\
\hline & & $\mathrm{SHP}_{\text {std }}$ & SHPDD $_{D}$ & $\mathrm{SHP}_{\mathrm{DD}+\mathrm{SD}}$ & $\begin{array}{l}\text { The } \\
\text { most } \\
\text { app* }\end{array}$ \\
\hline $\begin{array}{l}\text { Study } \\
\text { area }\end{array}$ & $\begin{array}{l}\text { RMS } \\
\text { (m) }\end{array}$ & $\begin{array}{l}\text { RMS } \\
(\mathrm{m})\end{array}$ & $\begin{array}{l}\text { RMS } \\
\text { (m) }\end{array}$ & $\begin{array}{l}\text { RMS } \\
\text { (m) }\end{array}$ & SHP \\
\hline Ham. & 0.32 & 0.35 & 0.31 & 0.28 & $\mathrm{DD}+\mathrm{SD}$ \\
\hline Kizıl. & 0.51 & 0.56 & 0.52 & 0.48 & $\mathrm{DD}+\mathrm{SD}$ \\
\hline Elik. & 0.81 & 0.73 & 0.77 & 0.72 & $\mathrm{DD}+\mathrm{SD}$ \\
\hline
\end{tabular}

$u$ : The most appropriate power parameters

* It is the approach with the smallest of RMS

When Table 5 is examined, an improvement is observed in the results when using SHPDD+SD approach, which takes into account the most appropriate power parameter and direction and slope factor in all three study areas. It was observed that the results of $\mathrm{SHP}_{\mathrm{DD}+\mathrm{SD}}$ approach provided 11\% improvement in Hamal and Eliktekke study area and 5\% in Kızılcakent study area compared to IDW $\mathrm{Itd}_{\mathrm{std}}(\mathrm{u}=2)$ results.

Table 6. RMS differences of $\operatorname{IDW}_{\text {std }}(\mathrm{u}=1)$ and $\mathrm{SHP}_{\mathrm{DD}+\mathrm{SD}}$ $(\mathrm{u}=1)$ interpolation methods

\begin{tabular}{|c|c|c|c|}
\hline \multirow{2}{*}{$\begin{array}{l}\text { Study } \\
\text { Area }\end{array}$} & \multicolumn{2}{|c|}{ RMS [m] } & \multirow{2}{*}{$\begin{array}{l}\text { RMS } \\
\text { Diffences [m] }\end{array}$} \\
\hline & $\begin{array}{l}I_{(\mathrm{IDW}} \mathrm{std} \\
(\mathrm{u}=1)\end{array}$ & SHPDD+SD (u=1) & \\
\hline Hamal & 0.363 & 0.285 & 0.078 \\
\hline Kizılcakent & 0.519 & 0.484 & 0.035 \\
\hline Eliktekke & 0.846 & 0.722 & 0.124 \\
\hline
\end{tabular}

In Table 6, the worst and best results and differences between them are given for the RMS values obtained as a result of interpolation methods. The difference values for the Hamal and Kizllcakent study sites were determined as 7.8 and $3.5 \mathrm{~cm}$, respectively. For these study areas, the expected maximum accuracy of vertical position error is 15.6 and $21.9 \mathrm{~cm}$, respectively. RMS differences are smaller than the expected maximum accuracy of vertical position error values, making the improvement in the average RMS value meaningless in these areas where the slope change is low. However, the mean RMS value of $12.4 \mathrm{~cm}$ decreased in the Eliktekke area where the slope change is high. Since the expected maximum accuracy of vertical position error value for this area is $4.2 \mathrm{~cm}$, the improvement in the RMS value of $12.4 \mathrm{~cm}$ can be considered as a significant improvement.

In order to more clearly understand the effect of the slope difference and the directional distribution between the interpolation point and reference points on the interpolation results, the points in the area where the directional distribution is disproportionate and the slope difference is higher between the interpolation point and the reference points in the critical circle, a detailed examination was made. For this purpose, firstly, the distribution of reference points falling within the critical circle around the interpolation point was taken into 
consideration. For this process, the bearing between the interpolation point and the reference points falling within the critical circle was calculated. Then, according to these bearing angles, it was determined to which region the reference points fell from 4 regions within the geodesic unit circle. Reference point numbers in four different regions were determined and the ratio of the number of reference points per region to the total number of reference points was calculated. Thus, the directional distribution rates of the points for 4 regions were determined. If the directional distribution ratio determined for any region is over $50 \%$, it is thought that there is a disproportionate distribution in the directional distribution between the reference points and the interpolation points. Interpolation points, which have a directional distribution over 50\% among all interpolation points, were determined in this way. With the same method, interpolation points with a directional distribution above $60 \%$ and $70 \%$ were also determined.
After determining the interpolation points whose directional distribution is disproportionate, the slope rates between these interpolation points and reference points were calculated. Interpolation points with a slope value of more than $5 \%, 10 \%, 15 \%$ and $20 \%$, respectively, were determined and divided into clusters. With these evaluations, the main dataset where the slope difference and directional distribution are not taken into account, three different datasets with only directional distribution above $50 \%, 60 \%$ and $70 \%$ regardless of slope difference and finally, with 12 different data sets, with slope differences over $5 \%, 10 \%, 15 \%, 20 \%$, and the directional distribution over $50 \%, 60 \%$ and $70 \%$ respectively, a total of 16 data sets were created. Using these datasets, the effect of both the slope difference and the directional distribution for different interpolation methods were examined in detail.

Table 7. RMS values obtained for different slope and directional distribution percentages by using interpolation approaches

\begin{tabular}{|c|c|c|c|c|c|c|c|c|c|c|c|c|c|c|}
\hline \multirow{2}{*}{$\begin{array}{l}\text { Estimation } \\
\text { approaches }\end{array}$} & \multirow{2}{*}{$\begin{array}{l}\text { Power } \\
\text { parameters } \\
\text { (u) }\end{array}$} & \multirow{2}{*}{$\begin{array}{l}\text { Slope } \\
(\%)\end{array}$} & \multicolumn{4}{|c|}{$\begin{array}{l}\text { HAMAL } \\
\text { Directional distribution (\%) }\end{array}$} & \multicolumn{4}{|c|}{$\begin{array}{l}\text { KIZILCAKENT } \\
\text { Directional distribution (\%) }\end{array}$} & \multicolumn{4}{|c|}{$\begin{array}{l}\text { ELİKTEKKE } \\
\text { Directional distribution (\%) }\end{array}$} \\
\hline & & & None & 50 & 60 & 70 & None & 50 & 60 & 70 & None & 50 & 60 & 70 \\
\hline \multirow{10}{*}{ IDW $_{\text {std }}$} & \multirow{5}{*}{2} & None & 0.321 & 0.424 & 0.639 & 0.530 & 0.511 & 0.595 & 0.517 & 0.683 & 0.811 & 0.853 & 1.560 & 1.745 \\
\hline & & 5 & - & 0.501 & 0.654 & 0.530 & - & 0.606 & 0.524 & 0.707 & - & 1.251 & 2.177 & 2.539 \\
\hline & & 10 & - & 0.701 & 0.755 & 0.844 & - & 0.760 & 0.772 & 0.819 & - & 1.478 & 2.387 & 2.692 \\
\hline & & 15 & - & 0.800 & 1.061 & 0.853 & - & 1.004 & 1.147 & 1.329 & - & 1.645 & 2.662 & 3.009 \\
\hline & & 20 & - & 1.123 & 1.267 & 1.299 & - & 1.166 & 1.484 & 2.172 & - & 1.706 & 2.662 & 3.009 \\
\hline & \multirow{5}{*}{ Optimal } & None & 0.321 & 0.424 & 0.444 & 0.483 & 0.511 & 0.595 & 0.504 & 0.494 & 0.808 & 0.843 & 1.368 & 1.643 \\
\hline & & 5 & - & 0.501 & 0.453 & 0.483 & - & 0.606 & 0.511 & 0.512 & - & 1.227 & 2.151 & 2.443 \\
\hline & & 10 & - & 0.639 & 0.493 & 0.494 & - & 0.760 & 0.672 & 0.603 & - & 1.412 & 2.357 & 2.589 \\
\hline & & 15 & - & 0.783 & 0.803 & 0.826 & - & 1.004 & 1.137 & 1.329 & - & 1.616 & 2.629 & 3.133 \\
\hline & & 20 & - & 0.922 & 1.267 & 1.248 & - & 1.156 & 1.484 & 2.172 & - & 1.610 & 2.629 & 3.133 \\
\hline \multirow{10}{*}{$\mathrm{SHP}_{\text {std }}$} & \multirow{5}{*}{2} & None & 0.380 & 0.490 & 0.483 & 0.537 & 0.606 & 0.682 & 0.590 & 0.490 & 0.896 & 0.991 & 1.795 & 1.907 \\
\hline & & 5 & - & 0.534 & 0.494 & 0.537 & - & 0.696 & 0.598 & 0.508 & - & 1.204 & 2.087 & 2.324 \\
\hline & & 10 & - & 0.632 & 0.705 & 0.527 & - & 0.925 & 0.661 & 0.840 & - & 1.332 & 2.286 & 2.460 \\
\hline & & 15 & - & 0.887 & 0.822 & 0.951 & - & 1.057 & 0.977 & 1.419 & - & 1.718 & 2.546 & 2.852 \\
\hline & & 20 & - & 0.957 & 1.484 & 1.438 & - & 1.378 & 1.388 & 2.243 & - & 1.474 & 2.546 & 2.852 \\
\hline & \multirow{5}{*}{ Optimal } & None & 0.354 & 0.487 & 0.447 & 0.512 & 0.556 & 0.627 & 0.499 & 0.459 & 0.731 & 0.806 & 1.365 & 1.279 \\
\hline & & 5 & - & 0.530 & 0.456 & 0.512 & - & 0.639 & 0.505 & 0.476 & - & 1.155 & 1.942 & 2.237 \\
\hline & & 10 & - & 0.632 & 0.499 & 0.498 & - & 0.832 & 0.661 & 0.597 & - & 1.304 & 2.124 & 2.366 \\
\hline & & 15 & - & 0.849 & 0.792 & 0.862 & - & 1.007 & 0.977 & 1.335 & - & 1.432 & 2.358 & 2.738 \\
\hline & & 20 & - & 0.957 & 1.446 & 1.280 & - & 1.267 & 1.354 & 2.085 & - & 1.474 & 2.358 & 2.738 \\
\hline \multirow{10}{*}{ SHPDD $_{D}$} & \multirow{5}{*}{2} & None & 0.355 & 0.474 & 0.470 & 0.523 & 0.592 & 0.665 & 0.589 & 0.475 & 0.901 & 0.995 & 1.798 & 1.909 \\
\hline & & 5 & - & 0.516 & 0.595 & 0.523 & - & 0.678 & 0.597 & 0.493 & - & 1.208 & 2.091 & 2.327 \\
\hline & & 10 & - & 0.648 & 0.673 & 0.511 & - & 0.867 & 0.648 & 0.824 & - & 1.335 & 2.290 & 2.463 \\
\hline & & 15 & - & 0.861 & 0.784 & 0.906 & - & 1.023 & 1.074 & 1.406 & - & 1.724 & 2.551 & 2.857 \\
\hline & & 20 & - & 0.916 & 1.456 & 1.370 & - & 1.339 & 1.345 & 2.237 & - & 1.480 & 2.551 & 2.857 \\
\hline & \multirow{5}{*}{ Optimal } & None & 0.314 & 0.450 & 0.447 & 0.512 & 0.517 & 0.549 & 0.478 & 0.417 & 0.772 & 0.862 & 1.365 & 1.279 \\
\hline & & 5 & - & 0.491 & 0.455 & 0.512 & - & 0.581 & 0.484 & 0.433 & - & 1.135 & 1.926 & 2.221 \\
\hline & & 10 & - & 0.600 & 0.499 & 0.498 & - & 0.781 & 0.531 & 0.588 & - & 1.309 & 2.106 & 2.348 \\
\hline & & 15 & - & 0.804 & 0.732 & 0.799 & - & 0.951 & 0.927 & 1.311 & - & 1.438 & 2.340 & 2.720 \\
\hline & & 20 & - & 0.916 & 1.363 & 1.184 & - & 1.196 & 1.291 & 2.077 & - & 1.479 & 2.340 & 2.720 \\
\hline \multirow{10}{*}{$\mathrm{SHP}_{\mathrm{DD}+\mathrm{SD}}$} & \multirow{5}{*}{2} & None & 0.318 & - & - & - & 0.514 & - & - & - & 0.807 & - & - & - \\
\hline & & 5 & - & 0.456 & 0.495 & 0.446 & - & 0.600 & 0.537 & 0.450 & - & 1.012 & 1.927 & 2.168 \\
\hline & & 10 & - & 0.540 & 0.558 & 0.584 & - & 0.775 & 0.578 & 0.780 & - & 1.312 & 2.108 & 2.292 \\
\hline & & 15 & - & 0.693 & 0.629 & 0.721 & - & 0.934 & 0.880 & 1.348 & - & 1.576 & 2.347 & 2.658 \\
\hline & & 20 & - & 0.749 & 1.213 & 1.034 & - & 1.164 & 1.234 & 2.135 & - & 1.459 & 2.347 & 2.658 \\
\hline & \multirow{5}{*}{ Optimal } & None & 0.285 & - & - & - & 0.484 & - & - & - & 0.722 & - & - & - \\
\hline & & 5 & - & 0.424 & 0.372 & 0.389 & - & 0.513 & 0.447 & 0.416 & - & 0.999 & 1.741 & 2.114 \\
\hline & & 10 & - & 0.534 & 0.558 & 0.381 & - & 0.702 & 0.487 & 0.499 & - & 1.139 & 1.900 & 2.234 \\
\hline & & 15 & - & 0.608 & 0.629 & 0.721 & - & 0.924 & 0.733 & 1.288 & - & 1.218 & 2.211 & 2.587 \\
\hline & & 20 & - & 0.720 & 1.173 & 1.034 & - & 1.098 & 1.234 & 2.048 & - & 1.275 & 2.211 & 2.587 \\
\hline
\end{tabular}

"_"There is no data or approach suitable for this condition. 
These 16 data sets were evaluated using, respectively, IDW $\mathrm{Itd}_{\text {std }}(\mathrm{u}=2), \mathrm{IDW}_{\text {std }}\left(\mathrm{u}=\right.$ optimal), $\mathrm{SHP}_{\text {std }}$ $(\mathrm{u}=2), \mathrm{SHP}_{\text {std }} \quad\left(\mathrm{u}=\right.$ optimal), SHPDD $_{\mathrm{D}}(\mathrm{u}=2), \mathrm{SHP}_{\mathrm{DD}}$ (u=optimal), SHP ${ }_{D D+S D}(u=2), S_{D D+S D}(u=o p t i m a l)$ interpolation approaches with the software developed. RMS values of these evaluation results are given in Table 7 collectively.

When Table 7 is examined, it is seen that the RMS value obtained from the evaluation of all data regardless of the slope and directional distribution data is the smallest values for all methods. Moreover, RMS values increase as slope and directional distribution percentages increase for all methods. As can be seen from here, the increase in slope and directional distribution percentages in all methods increases the RMS value. When directional distribution above 50\% with slope differences over $10 \%$, it is observed that the differences in RMS values are greater than the expected maximum accuracy of vertical position error values. This shows that the accuracy of the interpolation method is directly related to the slope and directional distribution of the data set.

To determine the relationship between the accuracy of the IDW based interpolation method and the slope and directional distribution of the data set, the coefficients $\left(\mathrm{p}_{\mathrm{nm}}\right)$ were calculated using the Matlab Curve Tool according to the model given in Eq. 7 .

$$
\begin{aligned}
& R M S=p_{00}+p_{10} * D D R+p_{01} * S R+p_{20} * D D R^{2} \\
& +p_{11} * D D R * S R+p_{02} * S R^{2}+p_{30} * D D R^{3} \\
& +p_{21} * D D R^{2} * S R+p_{12} * D D R * S R^{2}
\end{aligned}
$$

It shows $\mathrm{n}$ and $\mathrm{m}$ : degrees, $\mathrm{p}_{\mathrm{nm}}$ : coefficients, DDR: directional distribution rate, SR: slope difference and RMS: root mean square in Eq. 8. According to the mathematical model in Eq. 8, p $_{n m}$ coefficients were calculated for each approach. Then, $\mathrm{R}^{2}$ and RMS values of these modules were calculated to see the consistency of the models created according to Eq. 7 for each

\begin{tabular}{|c|c|c|c|c|c|c|c|}
\hline \multirow{2}{*}{$\begin{array}{l}\text { Estimation } \\
\text { approaches }\end{array}$} & \multirow{2}{*}{$\begin{array}{l}\text { Power } \\
\text { parameters } \\
\text { (u) }\end{array}$} & \multicolumn{2}{|c|}{ HAMAL } & \multicolumn{2}{|c|}{ KIZILCAKENT } & \multicolumn{2}{|c|}{ ELİKTEKKE } \\
\hline & & $\mathrm{R}^{2}$ & RMS (m) & $\mathrm{R}^{2}$ & RMS (m) & $\mathrm{R}^{2}$ & RMS (m) \\
\hline \multirow{2}{*}{ IDW $_{\text {std }}$} & 2 & 0.963 & 0.081 & 0.990 & 0.067 & 0.994 & 0.079 \\
\hline & Optimal & 0.981 & 0.059 & 0.989 & 0.074 & 0.987 & 0.122 \\
\hline \multirow{2}{*}{$\mathrm{SHP}_{\text {std }}$} & 2 & 0.967 & 0.090 & 0.997 & 0.037 & 0.988 & 0.096 \\
\hline & Optimal & 0.961 & 0.093 & 0.990 & 0.067 & 0.989 & 0.097 \\
\hline \multirow{2}{*}{ SHPDD } & 2 & 0.957 & 0.098 & 0.993 & 0.056 & 0.988 & 0.097 \\
\hline & Optimal & 0.958 & 0.088 & 0.992 & 0.060 & 0.989 & 0.096 \\
\hline \multirow{2}{*}{$S_{H P D+S D}$} & 2 & 0.927 & 0.012 & 0.998 & 0.032 & 0.998 & 0.037 \\
\hline & Optimal & 0.958 & 0.099 & 0.992 & 0.083 & 0.996 & 0.063 \\
\hline Mean & & 0.96 & 0.08 & 0.99 & 0.06 & 0.990 & 0.09 \\
\hline
\end{tabular}
approach. Calculated values are given in Table 8.

Table 8. $\mathrm{R}^{2}$ and RMS values estimated for approaches according to Eq. 7

When Table 8 is examined, it is seen that the average $\mathrm{R}^{2}$ values vary between $0.96-0.99$ and the average RMS values vary between $6 \mathrm{~cm}$ and $9 \mathrm{~cm}$. As can be understood from Eq. 7 and Table 8, the accuracy of IDW based interpolation approaches is in a polynomial relation with 3 rd degree slope factors and 2 nd degree with directional distribution. In Figure 12, polynomial relation and coefficient values calculated for $\operatorname{IDW}_{\text {std }}(\mathrm{u}=$ 2) approach with Matlab Curve Tool are given as examples.

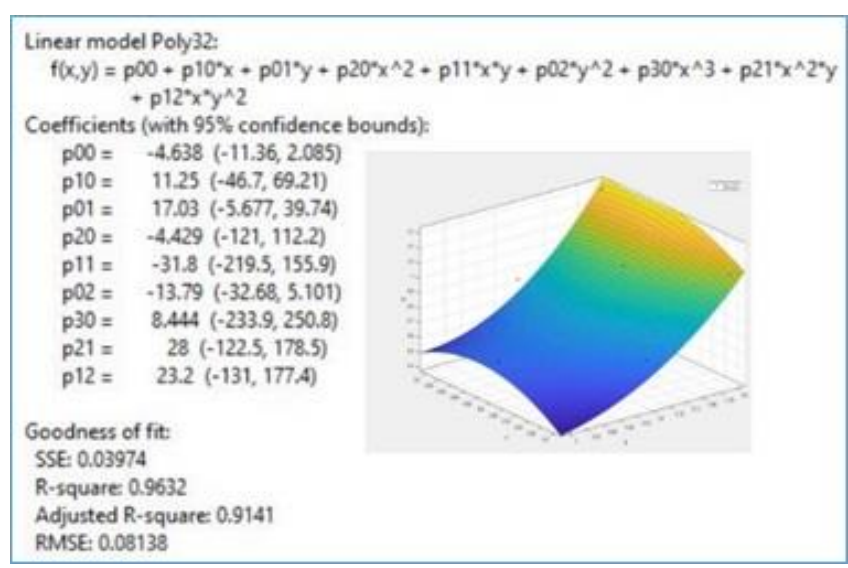

Figure 12. Polynomal relation and coefficient values calculated for the $\operatorname{IDW}_{\text {std }}(\mathrm{u}=2)$ model with Matlab Curve Tool
At this stage, the following questions arise. Does using the approaches developed by Shepard instead of IDW $_{\text {std }}(\mathrm{u}=2)$ method contribute positively to the estimation accuracy? If so, what is this rate? To answer these questions, $\operatorname{IDW}_{\text {std }}(\mathrm{u}=2)$ estimation results for the same datasets in Table 3 were compared with the estimation results of other Shepard approaches. For this, the improvement rates of the approaches were calculated by using Eq.8. The results are given in Table 6.

$$
R I R=\frac{\left(R M S_{I D W(u=2)}-R M S_{\text {approach }}\right)}{R M S_{I D W}(u=2)} \times 100
$$

In Eq. 8, RIR: Result improvement rate, $\mathrm{RMS}_{\text {approach: }}$ root mean square of approaches, $\mathrm{RMS}_{\mathrm{IDW}(\mathrm{u}=2)}$ : root mean square of IDW $_{\text {std }}(\mathrm{u}=2)$ approach.

Table 9 gives the calculated RIR values for the slope differences and directional distribution of three different study area. As can be seen from here, the rate of improvement of the estimation results of the approaches varies between $3 \%$ and $22 \%$. The SHPDD+SD ( $\mathrm{u}=$ optimal) approach gives the highest improvement rates of the estimation results 3-dimensional (Slope Difference - Directional Distribution - Result Improvement Rate) graphs of mean RIR values were drawn to better analyze and visually express improvement rates. In the drawing of the graphics, 
firstly a grid network was created then the grid corner values were estimated by linear interpolation method. Graphics created with the help of these values are given in Figure 13.

When Figure 13 is evaluated, it is seen that if the directional distribution is above about 55\% for all approaches, an increase in RIR values is observed, on the other hand, if the slope difference exceeds approximately $15 \%$, the increase trend in RIR values turns towards a decrease. However, it was seen that the highest RIR values were obtained from the SHP ${ }_{\mathrm{DD}+\mathrm{SD}}$ (optimal) approach (Table 9, Figure 13). The mean result improvement rate of $\mathrm{SHP}_{\mathrm{DD}+\mathrm{SD}}$ (optimal) approach is $22 \%$. Sorting of approaches results according to the result improvement rates are $\mathrm{SHP}_{\mathrm{DD}+\mathrm{SD}}$ (optimal), SHP $_{D D+S D}(\mathrm{u}=2), \mathrm{SHP}_{\mathrm{DD}}$ (optimal), SHP std (optimal), IDW $_{\text {std }}$ (optimal), $\operatorname{SHP}_{\mathrm{DD}}(\mathrm{u}=2), \mathrm{SHP}_{\text {std }}(\mathrm{u}=2)$.

Table 9. RIR values of approaches

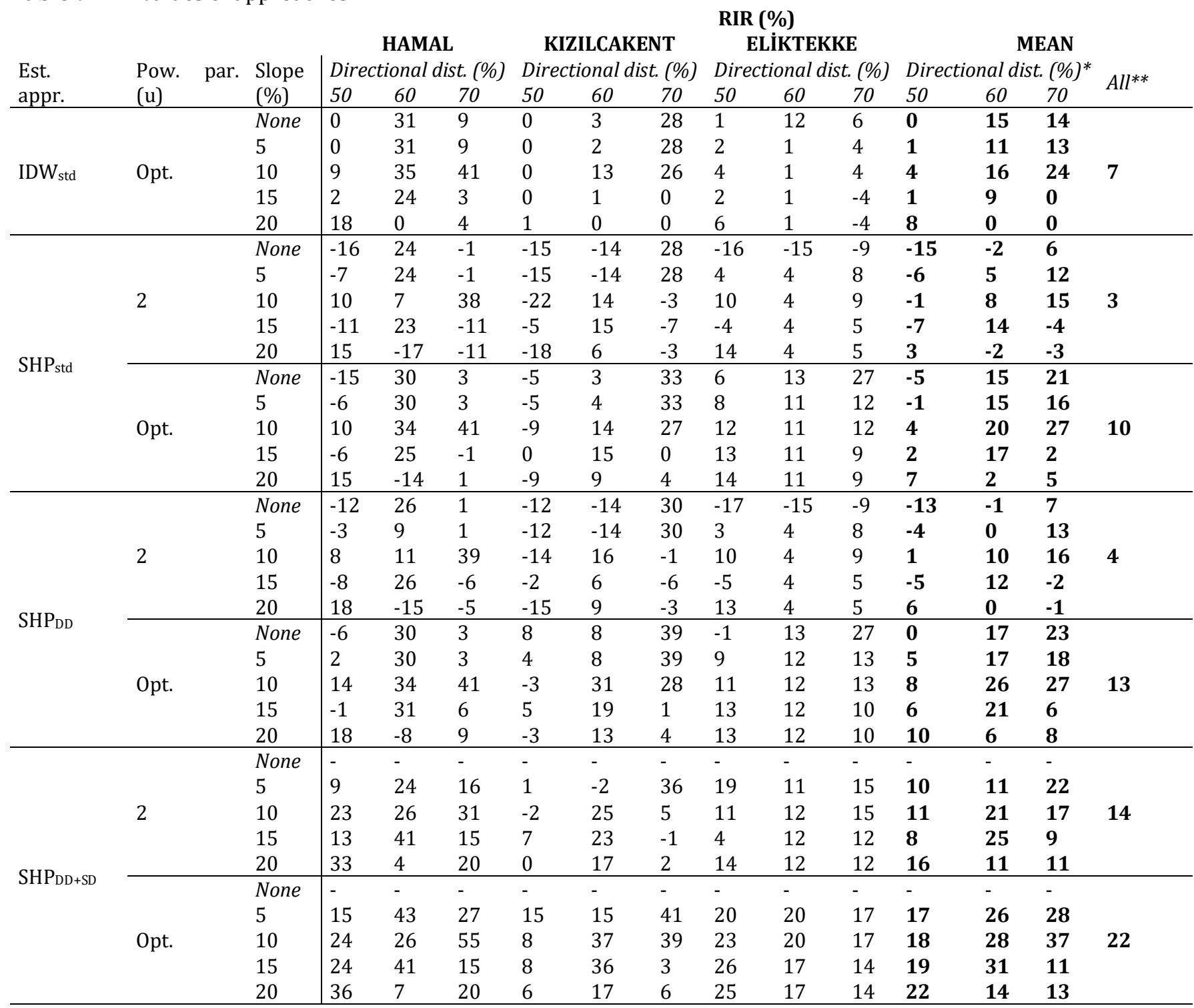

* Mean of result improvement rates for all three study areas.

** Mean of result improvement rates for each interpolation approaches. 

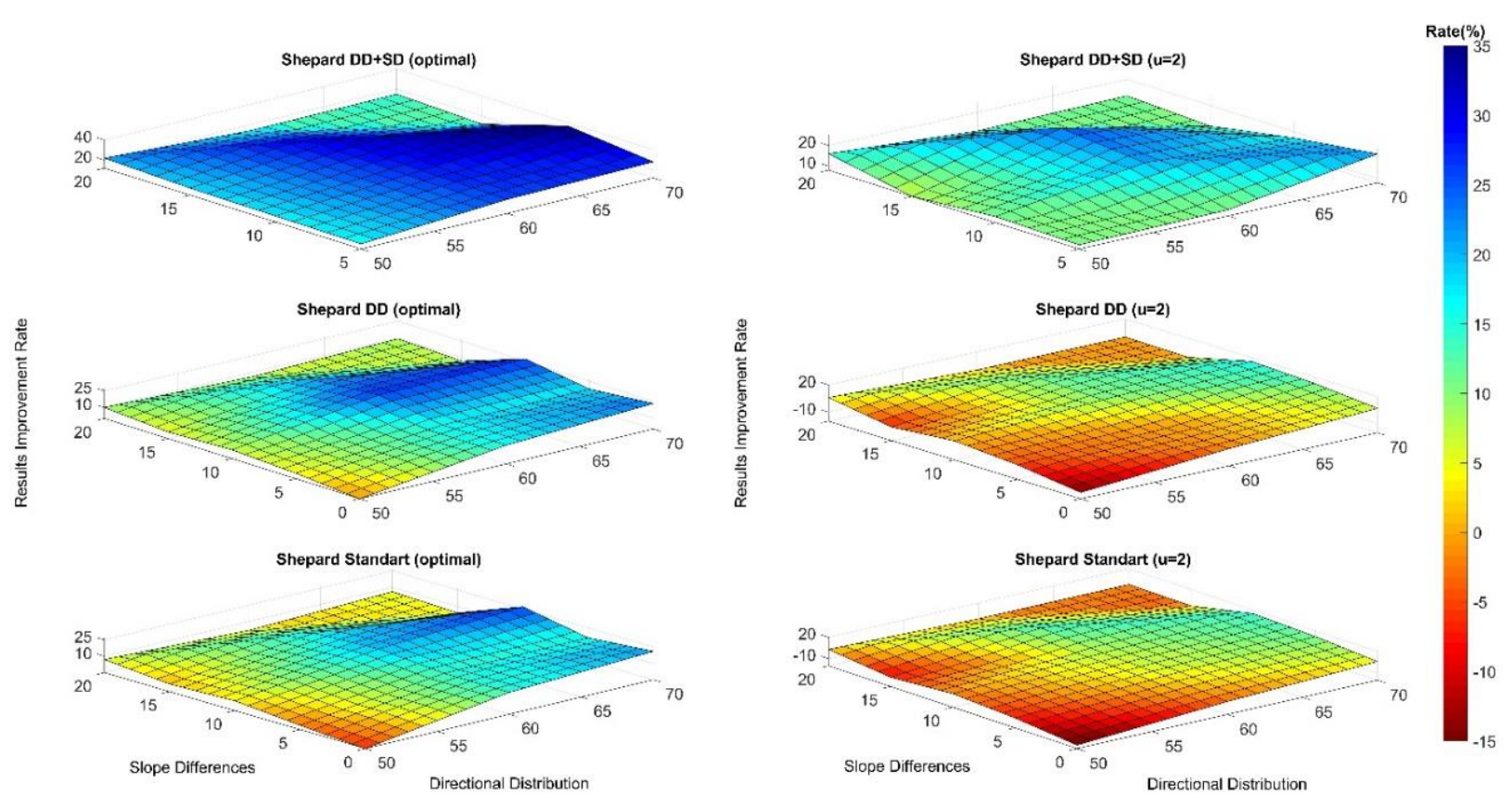

Figure 13. Three dimensional (Slope Difference, Directional Distribution, Result Improvement Rate) graphs for mean RIR values

\section{RESULTS}

The following results were obtained for interpolation approaches in this study conducted in three different

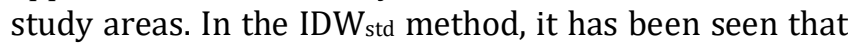
using different power parameters for each study site increases the estimation accuracy. The interpolation accuracy of the SHPstd approach, where the direction and slope factors are not taken into account, is lower than the $\mathrm{IDW}_{\text {std }}$ approach. The accuracy of the interpolation results obtained from the SHPDD approach, taking into account the directional distribution, is slightly improved compared to the SHPstd approach, but a noticeable improvement cannot be achieved compared to the IDW $_{\text {std }}$ method. In the SHP $P_{D+S D}(u=2)$ approach estimation results there was no significant improvement $(<5 \mathrm{~mm})$ compared to the results of the IDW $_{\text {std }}$ approach. The interpolation accuracy is improved when using " $u=1$ " instead of " $u=2$ " used in the literature for Shepard method in our study sites. In the Shepard method, which uses the slope change between the reference points and the directional distribution of the reference points in the weight calculation, if the interpolation is performed by determining the most appropriate power parameter (SHP $P_{D+S D}$ (u: optimal) approach), the results show an improvement between 5\% and $11 \%$ according to the $\mathrm{IDW}_{\text {std }}(\mathrm{u}=2)$ method. When all approaches are taken together, it is observed that in areas where slope differences between reference points increase, result improvement rates for $\mathrm{SHP}_{\mathrm{DD}+\mathrm{SD}}$ (u: optimal) approach improve proportionally with slope difference. For the accuracy of all IDW-based interpolation approaches used in this study was found a polynomial relationship with 2nd degree with directional distribution and 3rd degree with slope factors. For all the approaches used in the study, an increase in RIR values is observed if the directional distribution is above $55 \%$, besides this if the slope difference rises above about $15 \%$, the increase trend in RIR values turned towards a decrease. The best RIR value was obtained as $22 \%$ with SHPDD+SD (u: optimal) approach.

\section{CONCLUSION AND DISCUSSION}

Today, IDW method is used by many software. These software's use the standard IDW method, which takes the power parameter "2" for ease of calculation. Shepard approaches are not used by existing software. Using the software developed in this study, it was researched whether Shepard approaches provide an advantage over standard IDW method. The developed software can determine the most suitable inverse distance weight interpolation approach for each study area. The developed software is a first in terms of determining the most suitable inverse distance weight interpolation approach as well as calculating IDW approaches (IDW $_{\text {std }}$ and Shepard) according to different power parameters. Using this software, interpolations can be performed according to various IDW for the study areas. Thanks to this software, when the number of points falling within the critical circle falls below 4 in the Shepard approaches, the software automatically determines at least 4 reference points closest to the interpolation point from the reference point set and performs the interpolation process. In addition, while the power parameter is used as "2" standard in the Shepard approaches in the literature, calculations can be made by determining the most suitable power parameter for the study region in the developed software.

In order to test the success of the above-mentioned inverse distance weighted interpolation methods for UAV point clouds, tests were carried out in three different fields in this study. In the developed software, point cloud data produced by UAV photogrammetry belonging to three different study areas were used. By comparing the known height values with the estimated 
height values of the interpolation points, the reliability of the software algorithm developed with the accuracy of the interpolation methods was tested. These tests have shown that using a suitable power parameter in the study area instead of using a fixed power parameter in IDW approaches will increase the DEM estimation accuracy. However, in cases where the directional distribution is over $55 \%$ and the slope difference does not exceed $15 \%$, the results improved between $11 \%$ and $37 \%$ using the SHP ${ }_{D D+S D}$ (optimal) approach compared to the $\operatorname{IDW}_{\text {std }}(\mathrm{u}=2)$ method.

The results pointed out above show that using models that take into account field slope and directional distributions of reference points in IDW based interpolations will increase accuracy.

\section{ACKNOWLEDMENT}

We would like to thank GEOMINE R \& D Company for providing software and hardware support for this study. In this study, MATLAB software licensed by Sivas Cumhuriyet University was used.

\section{Author contributions}

Kemal Özgür Hastaoğlu: Conceptualization, Methodology, Software development. Statistical analysis. Sinan Göğsu: Data curation, Software development, Statistical analysis Writing-Original draft preparation. Yavuz Gül: Data curation, Visualization, Statistical analysis, Writing-Reviewing and Editing.

\section{Conflicts of interest}

The authors declare no conflicts of interest.

\section{REFERENCES}

Agüera-Vega F, Agüera-Puntas M, Mancini F, MartínezCarricondo P \& Carvajal-Ramírez F (2019). Effects of Structure from Motion Data density, interpolation method and grid size on micro topography Digital Terrain Model accuracy. Preprints doi: 10.20944/preprints 201908.0283.v1.

Arun P V (2013). A comparative analysis of different DEM interpolation methods. The Egyptian Journal of Remote Sensing and Space Science, 16(2), 133-139.

Bater C W \& Coops N C (2009). Evaluating error associated with lidar-derived DEM interpolation. Computers \& Geosciences, 35(2), 289-300.

Brimicombe A (2009). GIS, environmental modeling and engineering. CRC Press

Chen F W \& Liu C W (2012). Estimation of the spatial rainfall distribution using inverse distance weighting (IDW) in the middle of Taiwan. Paddy and Water Environment, 10(3), 209-222.

Das M, Hazra A, Sarkar A, Bhattacharya S \& Banik P (2017). Comparison of spatial interpolation methods for estimation of weekly rainfall in West Bengal, India. Mausam, 68(1), 41-50.

Envir. Sys. Res. Inst: How IDW Works (2020). https://desktop.arcgis.com/en/arcmap/10.3/tools/ 3d-analyst-toolbox/how-idw-orks.htm . Accessed 04 February 2020
Ferreira I O, Rodrigues D D, Santos G R D, \& Rosa L M F (2017). In bathymetric surfaces: IDW or Kriging? Boletim de Ciências Geodésicas, 23(3), 493-508.

Guo Q, Li W, Yu H \& Alvarez O (2010). Effects of topographic variability and lidar sampling density on several DEM interpolation methods. Photogrammetric Engineering \& Remote Sensing, 76(6), 701-712.

Graham A N, Coops N C, Tompalski P, Plowright A \& Wilcox M (2020). Effect of ground surface interpolation methods on the accuracy of forest attribute modelling using unmanned aerial systemsbased digital aerial photogrammetry. International Journal of Remote Sensing, 41(9), 3287-3306.

Habib A, Khoshelham K, Akdim N, Labbassi K \& Menenti $M$ (2018). Impact of spatial resolution, interpolation and filtering algorithms on DEM accuracy for geomorphometric research: a case study from SahelDoukkala, Morocco. Modeling Earth Systems and Environment, 4(4), 1537-1554.

Ikechukwu M N, Ebinne E, Idorenyin U \& Raphael N I (2017). Accuracy assessment and comparative analysis of IDW, spline and kriging in spatial interpolation of landform (Topography): An experimental study. Journal of Geographic Information System, 9(03), 354.

Ismail Z, Abdul Khanan M F, Omar F Z, Abdul Rahman M Z \& Mohd Salleh M R (2016). EVALUATING ERROR OF LIDAR DERIVED DEM INTERPOLATION FOR VEGETATION AREA. International Archives of the Photogrammetry, Remote Sensing \& Spatial Information Sciences, 42.

Liao Y, Li D \& Zhang N, 2018." Comparison of interpolation models for estimating heavy metals in soils under various spatial characteristics and sampling methods". Transactions in GIS, 22(2), 409434.

Lu G Y \& Wong D W (2008). An adaptive inverse-distance weighting spatial interpolation technique. Computers \& geosciences, 34(9), 1044-1055.

Meng Y, Cave M \& Zhang C (2019). Comparison of methods for addressing the point-to-area data transformation to make data suitable for environmental, health and socio-economic studies. Science of The Total Environment, 689, 797807.

Michael S (2020). GRASS Development Team: GRASS GIS 7.6.2 dev Reference Manual. https://grass.osgeo.org/grass76/manuals/v.surf.id w.html. Accessed 04 February 2020

Mohamed K S, Sajikumar K K, Ragesh N, Ambrose T V, Jayasankar J, Said Koya K P \& Sasikumar G (2018). Relating abundance of purpleback flying squid Sthenoteuthis oualaniensis (Cephalopoda: Ommastrephidae) to environmental parameters using GIS and GAM in south-eastern Arabian Sea. Journal of Natural History, 52(29-30), 1869-1882.

Paul R, Brindha K, Gowrisankar G, Tan M L \& Singh M K (2019). Identification of hydrogeochemical processes controlling groundwater quality in Tripura, Northeast India using evaluation indices, GIS, and multivariate statistical methods. Environmental Earth Sciences, 78(15), 1-16. 
Sarkar S, Parihar S M \& Dutta A (2016). Fuzzy risk assessment modelling of East Kolkata Wetland Area: A remote sensing and GIS based approach. Environmental modelling \& software, 75, 105-118.

Setianto A S \& Triandini T T (2013). Comparison of kriging and inverse distance weighted (IDW) interpolation methods in lineament extraction and analysis. Journal of Southeast Asian Applied Geology, 5(1), 21-29.

Shepard D (1968). A two-dimensional interpolation function for irregularly-spaced data. In Proceedings of the 1968 23rd ACM national conference (pp. 517524).

Stafford JV (2013) Precision agriculture'13. Wageningen Academic Publishers

Tran Q B \& Nguyen T T (2008). Assessment of the influence of interpolation techniques on the accuracy of digital elevation model. VNU Journal of Science. Earth Sciences 24, 176-183.

Wang G \& Huang L (2012). 3D geological modeling for mineral resource assessment of the Tongshan $\mathrm{Cu}$ deposit, Heilongjiang Province, China. Geoscience Frontiers, 3(4), 483-491.

Welch M C, Kwan P W \& Sajeev A S M (2014). Applying GIS and high-performance agent-based simulation for managing an Old-World Screwworm fly invasion of Australia. Acta tropica, 138, 82-93.

Wu C Y, Mossa J, Mao L \& Almulla M (2019). Comparison of different spatial interpolation methods for historical hydrographic data of the lowermost Mississippi River. Annals of GIS, 25(2), 133-151.

Zhou M, Guan H, Li C, Teng G \& Ma L (2017). An improved IDW method for linear array 3D imaging sensor. In 2017 IEEE International Geoscience and Remote Sensing Symposium (IGARSS) (pp. 3397-3400). IEEE.

Url-1 $<$ https://support.PIX4d.com/hc/enus/articles/202558889-Accuracy-of-PIX4Doutputs >, date of access: 2020 